\title{
DNA binding-dependent glucocorticoid receptor activity promotes adipogenesis via Krüppel-like factor 15 gene expression
}

\author{
Maki Asada 1,2,5, Alexander Rauch ${ }^{3,5}$, Hirohito Shimizu ${ }^{1}$, Hiromi Maruyama ${ }^{1}$, Shigeru Miyaki ${ }^{4}$, Masafumi Shibamori ${ }^{2}$, \\ Hideki Kawasome ${ }^{2}$, Hironobu Ishiyama ${ }^{2}$, Jan Tuckermann ${ }^{3,6}$ and Hiroshi Asahara ${ }^{1,4,6}$
}

Glucocorticoids, such as dexamethasone, have been used as in vitro inducers of adipogenesis. However, the roles of the glucocorticoid receptor (GR) in adipogenesis have not been well characterized yet. Here, we show that inhibition of GR activity using the GR antagonist RU486 prevents human mesenchymal stem cell and mouse embryonic fibroblast (MEF) differentiation into adipocytes. Moreover, in MEFs isolated from GR knockout (GR ${ }^{\text {null }}$ ) and $G^{\text {dim }}$ mice deficient in GR DNAbinding activity, adipogenesis was blocked. We identified glucocorticoid response element sites in the first intron of KLF15 by bioinformatical promoter analysis and confirmed their functional relevance by demonstrating GR interaction by chromatin immunoprecipitation. Moreover, transfection of MEFs with siRNA for KLF15 significantly attenuated the expressions of adipogenic-marker genes and the lipid accumulation. Our results provide a new mechanism for understanding glucocorticoids-dependent adipogenesis and that GR promotes adipogenesis via KLF15 gene expression as a transcriptional direct target.

Laboratory Investigation (2011) 91, 203-215; doi:10.1038/labinvest.2010.170; published online 18 October 2010

KEYWORDS: adipogenesis; bioinformatics analysis; glucocorticoid receptor; human mesenchymal stem cell; Krüppel-like factor 15; mouse embryonic fibroblast

Adipose tissue has a key role in the regulation of energy balance and mobilization as well as the endocrine regulation of nutrient intake. Because of its role in obesity and the metabolic syndrome, there is increasing interest in adipocyte biology, including the differentiation of adipose tissue.

It is well established that fibroblastic cells including 3T3L1, mesenchymal stem cells, and mouse embryonic fibroblasts (MEFs) can be differentiated into adipocytes under exposure to adipogenic inducers such as fetal bovine serum (FBS), dexamethasone (Dex), 3-isobutyl-1-methylxanthine (IBMX), and insulin. ${ }^{1-4}$ This adipogenesis process is tightly regulated by the complicated temporal expression of transcription factors. ${ }^{5-7}$ Among them, the peroxisome proliferator-activated receptor $\gamma(\operatorname{PPAR} \gamma)$ and CCAAT/enhancerbinding protein $\alpha(\mathrm{C} / \mathrm{EBP} \alpha)$ have been shown to have critical roles in adipogenesis. ${ }^{8,9}$ These two proteins act synergistically in the transcriptional activation of various adipocyte-specific genes. ${ }^{10}$ In addition, two other members of the C/EBP family, $\mathrm{C} / \mathrm{EBP} \beta$ and $\mathrm{C} / \mathrm{EBP} \delta$, are induced earlier than $\mathrm{C} / \mathrm{EBP} \alpha$ and PPAR $\gamma$ just after adipogenic stimulation. The ectopic expression of $\mathrm{C} / \mathrm{EBP} \beta$ and $\mathrm{C} / \mathrm{EBP} \delta$ promotes the expression of PPAR $\gamma$ and $\mathrm{C} / \mathrm{EBP} \alpha$ in fibroblasts and 3T3-L1, ${ }^{11-13}$ suggesting that $\mathrm{C} / \mathrm{EBP} \beta$ and $\mathrm{C} / \mathrm{EBP} \delta$ are upstream transcriptional regulators for $\mathrm{PPAR} \gamma$ and $\mathrm{C} / \mathrm{EBP} \alpha$

Glucocorticoids are potent regulators of adipose differentiation both in vitro and in vivo. ${ }^{14-16}$ The synthetic glucocorticoid Dex is widely used as a component of the adipogenic-induction cocktail for in vitro adipogenesis systems. Cao et al $^{11}$ have shown that treatment of 3T3-L1 preadipocytes with Dex activates $\mathrm{C} / \mathrm{EBP} \delta$, suggesting that the

\footnotetext{
${ }^{1}$ Department of Systems Biomedicine, National Institute of Child Health and Development, Tokyo, Japan; ${ }^{2}$ The Third Institute of New Drug Discovery, Otsuka Pharmaceutical, Tokushima, Japan; ${ }^{3}$ Group of Tissue Specific Hormone Action, Leibniz Institute for Age Research, Fritz Lipmann Institute, Jena, Germany and ${ }^{4}$ Department of Molecular and Experimental Medicine, The Scripps Research Institute, San Diego, CA, USA

Correspondence: Dr J Tuckermann, Leibniz Institute for Age Research, Fritz Lipmann Institute (FLI), Beutenbergstr. 11, D-07743 Jena, Germany; e-mail: jan@fli-leibniz.de or Dr H Asahara, MD, PhD, Department of Systems Biomedicine, National Institute of Child Health and Development, 2-10-1 Okura, Setagaya-ku, Tokyo 157-8535, Japan; e-mail: asahara@nch.go.jp

${ }^{5}$ These authors contributed equally to this work.

${ }^{6}$ These authors contributed equally to this work.
} 
potential mechanism of the role of Dex in adipogenesis is to enhance PPAR $\gamma$ and $\mathrm{C} / \mathrm{EBP} \alpha$ expression via promoting $\mathrm{C} / \mathrm{EBP} \delta$ expression. ${ }^{12}$ In a mesenchymal progenitor cell line, Dex induced $\mathrm{C} / \mathrm{EBP} \alpha, \mathrm{C} / \mathrm{EBP} \beta$, and $\mathrm{C} / \mathrm{EBP} \delta$, which lead to an increase in PPAR $\gamma$ and aP2 to induce adipocyte differentiation. ${ }^{17}$

Glucocorticoids exert their effects through the glucocorticoid receptor (GR), a ligand-activated transcription factor that belongs to the nuclear receptor superfamily. ${ }^{18,19}$ Molecular functions of the GR can be divided into two main actions; a transcriptional activator as a dimer and a transcriptional repressor as a monomer. As an activator, the ligand-bound GR binds to palindromic glucocorticoid response elements (GREs) as a dimer, thereby promoting target genes' transcription. ${ }^{20-23}$ Dimerization depends on the D-loop in the DNA-binding domain. Transcriptional repression by GR appears to be mediated by GR monomers' protein-protein interaction with other transcription factors, and neither needs dimerization nor DNA binding. GR dimerizaion activity is abolished by an amino-acid substitution in the GR D-loop (A458T) ${ }^{24}$ In mice carrying this point mutation (GR ${ }^{\mathrm{dim}}$ mice), GRE binding-dependent gene expression is impaired, but the monomer GR function, that is, cross-talk with other transcription factors (proteinprotein interaction), is maintained. ${ }^{25}$ To get insight into the precise molecular mechanism of adipogenesis triggered by Dex, we used MEF from two GR-mutant mice; GR-deficient $\left(\mathrm{GR}^{\text {null }}\right)$ mice and $\mathrm{GR}^{\mathrm{dim}}$ mice. These tools allow us to characterize direct GR-target genes in adipogenesis.

Among the set of GR targets during adipogenesis screened in this study, we focused on the role of KLF15, a member of the Krüppel-like family of transcription factors. Krüppel-like factors (KLFs) have diverse roles in cell proliferation, cell differentiation, and development. Some members of KLFs, such as KLF2, ${ }^{26} \mathrm{KLF} 5,{ }^{27}$ and $\mathrm{KLF} 15^{28}$ have been implicated in adipogenesis. KLF15 has previously been shown to regulate adipogenesis by inducing GLUT4 $4^{29}$ and PPAR $\gamma^{28}$ expression in 3T3-L1 preadipocytes; $\mathrm{KLF}^{-1} 5^{-1}$ mice exhibit severe hypoglycemia after an overnight fast. ${ }^{30}$ Previous studies revealed that KLF15 is induced by ectopic expression of $\mathrm{C} / \mathrm{EBP} \delta$ and $\mathrm{C} / \mathrm{EBP} \beta$, Dex treatment, and cAMP hormonal stimulation in 3T3-L1 cells. ${ }^{28}$ However, the molecular mechanism for the promotion of KLF15 gene expression is still unknown.

Here, we report that glucocorticoid stimulation was required for in vitro adipogenesis and GR activation with glucocorticoids induced KLF15 gene expression in a DNAdependent manner.

\section{MATERIALS AND METHODS Reagents and Cells}

Dex, IBMX, insulin, and RU486 were obtained from SigmaAldrich (St Louis, MO, USA). Pioglitazone was obtained from ALEXIS Biochemicals (Lausen, Switzerland). BMGM culture media for human mesenchymal stem cells (hMSCs) were obtained from Cambrex Bio Science Walkersville (Walkersville, MD, USA). Mouse embryonic fibroblast (MEF) cells from $\mathrm{GR}^{\text {null }}$ mice and $\mathrm{GR}^{\mathrm{dim}}$ mice were isolated as described. ${ }^{31}$ The 293T cell line was obtained from American Type Culture Collection. Anti-GR antibody (sc-1002) for chromatin immunoprecipitation (ChIP) was obtained from Santa Cruz Biotechnology (Santa Cruz, CA, USA). ${ }^{32}$

\section{Cell Culture and Differentiation}

hMSCs were maintained in BMGM culture media, and cells from passages 3-6 were used for experiments. MEFs were isolated from 13.5-day-old embryos obtained from C57BL/6 mice as described previously. ${ }^{33}$ Briefly, after dissection of head and visceral organs, embryos were minced and trypsinized for $30 \mathrm{~min}$ at $37^{\circ} \mathrm{C}$. Embryonic fibroblasts were filtered, plated, and maintained in Dulbecco's modified Eagle medium (DMEM) with $10 \%$ fetal calf serum, $100 \mathrm{U} / \mathrm{ml}$ penicillin, and $100 \mu \mathrm{g} / \mathrm{ml}$ streptomycin at $37^{\circ} \mathrm{C}$ in an atmosphere of $5 \%$ $\mathrm{CO}_{2}$. All experiments with wild-type, $\mathrm{GR}^{\text {null }}$ and $\mathrm{GR}^{\mathrm{dim}} \mathrm{MEF}$ were performed with cells in passages 2-10. For adipocyte differentiation, 2-day post-confluent cells were incubated for 3 days in adipogenesis-inducing medium (AIM), consisting of DMEM supplemented with $10 \%$ FBS, $500 \mu \mathrm{M}$ IBMX, $1 \mu \mathrm{M}$ Dex, $10 \mu \mathrm{M}$ pioglitazone, $10 \mu \mathrm{g} / \mathrm{ml}$ insulin. Cells were then incubated in adipogenesis maintenance medium (DMEM supplemented with $10 \% \mathrm{FBS}, 10 \mu \mathrm{g} / \mathrm{ml}$ insulin) for 4 days, with a fresh change of medium after 2 days (MEFs), or for 3 days (hMSCs); cells were then returned to AIM. Subsequently, lipid accumulation was visualized using Oil Red O stain as described previously. ${ }^{34}$ Nile Red staining was performed to quantify lipid accumulation. PFA-fixed cells were incubated with $1: 1000$ of a Nile Red stock $(0.5 \mathrm{mg} / \mathrm{ml}$ in acetone) in $80 \%$ glycerol $20 \%$ water and $1 \mathrm{mg} / \mathrm{ml}$ DAPI for nuclear counter staining. Lipid droplets were analyzed using Cellomics automated fluorescent microscopy. Cell numbers were counted according to DAPI staining and Nile red stained objects $>5.16 \mu \mathrm{m}$ were considered as lipid droplets and their fluorescent intensity was determined.

\section{Quantitative RT-PCR}

Total RNA was extracted using Isogen (Wako, Osaka, Japan), and $2 \mu \mathrm{g}$ RNA was used for cDNA synthesis with oligo(dT) 18 primer by the Ready-to-Go You-First cDNA kit (GE Healthcare Life Sciences, Uppsala, Sweden), according to the manufacturer's instructions. Quantitative real-time RT-PCR was performed using TaqMan Gene Expression Assay probe for Adiponectin (Hs00605917_m1), C/EBP $\alpha$ (Hs00269972_s1), C/

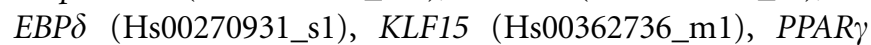
(Hs01115513_m1), GAPDH (Hs99999905_m1), mAdiponectin (Mm00456425_m1), $m C / E B P \alpha\left(\mathrm{Mm} 01265914 \_s 1\right), \mathrm{mC} / \mathrm{EBP} \delta$ (Mm00786711_s1), $\quad m G R \quad$ (Mm00433832_m1), $\quad m H I F 3 \alpha$ (Mm00469373_m1), mKLF9 (Mm00495172_m1), mKLF15

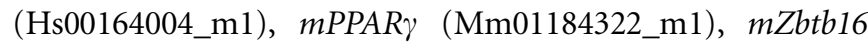
(Mm01176868_m1), $m Z h x 3$ (Mm00770117_m1), and mGAPDH (Mm99999915_g1) (All Applied Biosystems, 
Carlsbad, CA, USA). Relative expression was calculated using the $\Delta \Delta \mathrm{Ct}$ values, and results were expressed as $2-\Delta \Delta \mathrm{Ct}$. $G A P D H$ was used as an internal control to normalize differences in each sample. The value of each control sample was set at 1 and was used to calculate the fold change in target genes. For the results in Figures $2 \mathrm{c}, 4 \mathrm{~b}$ and $\mathrm{d}$ and Supplementary Figure 3, quantitative RT-PCR was performed as described. ${ }^{35}$ Primer information can be provided upon request. Data were analyzed statistically using the Mann-Whitney $U$ test or Steel-Dwass' test (multiple comparison). $P$-values $<0.05$ were considered statistically significant.

\section{Microarray Data Analysis}

To generate first-strand cDNA, each reaction contained T7linked oligo(dT) primers and $5 \mu \mathrm{g}$ total RNA (Affymetrix, Santa Clara, CA, USA). After second-strand synthesis using the SuperScript cDNA system (Invitrogen, Carlsbad, CA, USA), in vitro transcription was performed with biotinylated UTP and CTP (Enzo Life Sciences, New York, NY, USA), resulting in $\sim 20$-fold amplification of RNA. The biotinylated cRNA targets $(20 \mu \mathrm{g})$ were then cleaned up, fragmented, and hybridized to GeneChip expression arrays (Mouse Genome 4302.0 Array, Affymetrix). Arrays were then washed and stained with streptavidin phycoerythrin before being scanned on an Affymetrix GeneChip scanner. Gene expression was analyzed using the GeneSpring Software 7 (Agilent Technologies, Santa Clara, CA, USA). Genes with signal intensities below 50 were eliminated and normalized, and then genes from cells incubated with AIM or Dex treatment that exhibited at least a twofold change relative to the control treatment were selected for analysis. In addition, genes from cells incubated with AIM and RU486 treatment (adipogenesis-RU486-regulated group) that exhibited at least a twofold change compared with cells incubated in AIM were also selected. Genes that belong to both the adipogenesis-RU486 treatment group and Dex-treated group were identified as GR-regulated adipogenic genes.

\section{Location Analysis of the Promoter Sequences of KLF15 gene}

Promoter regions (from $-7500 \mathrm{bp}$ to $+2000 \mathrm{bp}$ ) of GRregulated adipogenic genes conserved between mouse and human genome were analyzed using rVista 2.0 and visualized using the ECR browser (http://ecrbrowser.dcode.org/). Mat Inspector software searched the highly conserved region for putative GRE sites (Genomatix, Munich, Germany). These GRE sites included androgen receptor (AR) response elements (AREs) and progesterone receptor (PR) response elements, because GR, AR, and PR bind to a consensus sequence for the superfamily of steroid hormone receptors.

\section{Chromatin Immunoprecipitation}

ChIP assays were performed as previously described. ${ }^{36,37}$ MEFs were washed with PBS and then cross-linked using $1 \%$ formaldehyde for $10 \mathrm{~min}$. The cross-linking was quenched with glycine (final concentration, $0.125 \mathrm{M}$ ). The samples were then washed twice in PBS and homogenized in ChIP cell lysis buffer ( $5 \mathrm{mM}$ PIPES ( $\mathrm{pH} 8.0$ ), $85 \mathrm{mM} \mathrm{KCl,} \mathrm{0.5 \%} \mathrm{Nonidet}$ $\mathrm{P}-40$, and protease inhibitor cocktail). Nuclei were sedimented and separated from the cellular debris, and then placed into nuclear lysis buffer $(50 \mathrm{mM}$ Tris $\mathrm{HCl}(\mathrm{pH} 8.1)$, $10 \mathrm{mM}$ EDTA, $1 \%$ SDS, $10 \mu \mathrm{M}$ aprotinin, $10 \mu \mathrm{M}$ leupeptin, and $1 \mathrm{mM}$ phenylmethylsulfonyl fluoride). After $10 \mathrm{~min}$ on ice, the lysate was sonicated on ice (Digital Sonifier; BRANSON, Danbury, CT, USA) using three pulses of $2 \mathrm{~s}$ each at $4-6 \mathrm{~W}$, and then centrifuged for $20 \mathrm{~min}$ at $21000 \mathrm{~g}$ at $4^{\circ} \mathrm{C}$. The supernatant was collected as chromatin samples. At this point, one aliquot was reserved as the input sample. When visualized on an agarose gel, the DNA produced a smear of fragments 200-600 bp long. For each immunoprecipitation reaction, $2 \mu \mathrm{g}$ of chromatin was used. The chromatin was precleared by incubating with protein- $\mathrm{G}$ agarose at $4^{\circ} \mathrm{C}$ for $1 \mathrm{~h}$. Antiserum raised against the GR or preimmune $\operatorname{IgG}$ were added $\left(2 \mu \mathrm{g}\right.$ each), and the samples were rotated at $4{ }^{\circ} \mathrm{C}$ overnight. Immunoprecipitates were isolated by incubating with blocked protein-G agarose and then washed extensively. Chromatin was eluted from the antibody by incubating for $10 \mathrm{~min}$ at room temperature with elution buffer $(0.1 \mathrm{M}$ $\mathrm{NaHCO}_{3}$ and $1 \%$ SDS). Cross-linking was reversed with $\mathrm{NaCl}\left(0.2 \mathrm{M}\right.$, final concentration) and incubating at $65^{\circ} \mathrm{C}$ for at least $4 \mathrm{~h}$. Samples were then digested with $40 \mathrm{ng}$ of proteinase $\mathrm{K}$, and DNA was isolated via phenol/chloroform extraction followed by ethanol precipitation. DNA concentrations were calculated by measuring absorbance at $260 \mathrm{~nm}$. PCR primer pairs used were $5^{\prime}$-GCACGCTGACC CAATGGC- $3^{\prime}$ and $5^{\prime}$-AGGCCGCTGGACTCCG- $3^{\prime}$ for the GRE1 site (+ 980/ + 998), 5'-CGGAGTCCAGCGGCCT-3', and $5^{\prime}$-GATCCAGGACTTCCTGGACCC- $3^{\prime}$ for the GRE2 site $(+1085 /+1103)$ in the first intron of the KLF15 gene.

\section{Luciferase Reporter Assay}

The mouse KLF15 enhancer region $(+933 /+1216)$ was amplified by PCR using genomic DNA from C57BL/6 mice, with the sense primer $5^{\prime}$-GCACGCTGACCCAATGGC- $3^{\prime}$ and the antisense primer $5^{\prime}$-GATCCAGGACTTCCTGGACCC- $3^{\prime}$ and then inserted into the pTA vector (TOYOBO, Osaka, Japan). This plasmid was digested with NheI and XhoI restriction enzymes and ligated into the luciferase expression vector pGL3-tk, which had been constructed by insertion of the thymidine kinase (TK) promoter from the herpes simplex virus (HSV) into pGL3-Basic (Promega). The GR-binding site of the KLF15 enhancer region was mutated using the KOD mutagenesis kit according to the manufacturer's recommendations (TOYOBO). This mutation changed the wild-type sequence $5^{\prime}$-ATTACATGTTGTTCC- $3^{\prime}$ to $5^{\prime}$-AC AACATGTTCATCC- $3^{\prime}$ for GRE1 and the wild-type sequence $5^{\prime}$-AGAACAGGGTGCCCC- $3^{\prime}$ to $5^{\prime}$-ACAACAGGGTCACCC- $3^{\prime}$ for GRE2. For the transfection experiment, 293T cells were plated into 96-well plates at $1 \times 10^{3}$ cells/well, and transient transfections were performed the following day using FuGENE 
HD (Roche Applied Science, Indianapolis, IN, USA). The total amount of plasmid used for the transfection assay per well was $0.1 \mu \mathrm{g}$ reporter vector $/ 0.01 \mu \mathrm{g}$ GR expression vector or pcDNA3.1 (Invitrogen)/phRL-TK vector (Promega). On the following day, $100 \mathrm{nM}$ Dex or vehicle (DMSO) were added to cells. After $24 \mathrm{~h}$, luciferase assays were carried out using Dual-Glo Luciferase Assay kit (Promega). The GR-dependent promoter activity of each construct was expressed as the ratio of activity in Dex/activity in DMSO. All luciferase experiments were performed in triplicate. Statistical significance of the difference between pGL3-intKLF15-tk and mutant reporters was determined by Steel's test.

\section{Transfection of siRNA for KLF15 into MEFs}

siRNA for KLF15 (siKLF15) (Silencer Select siRNAs-s82946, Applied Biosystems) and negative siRNA (Silencer Select siRNAs Silencer Negative Control \#1, Applied Biosystems) were transfected into MEFs at $80-90 \%$ confluence ( $50 \mathrm{nM}$ concentration) with Lipofectamine RNAi Max (Invitrogen) according to the manufacturer's instructions. After $48 \mathrm{~h}$, transfected MEFs were stimulated with AIM or control medium.

\section{RESULTS \\ Inhibition of Adipogenesis by GR Antagonist RU486 in hMSCs and MEFs}

To investigate the role of GR in adipocyte differentiation, hMSCs were induced to differentiate into adipocytes by incubation in adipogenic-induction medium containing $500 \mu \mathrm{M}$ IBMX, $1 \mu \mathrm{M}$ Dex, $10 \mu \mathrm{M}$ pioglitazone, $10 \mu \mathrm{g} / \mathrm{ml}$ insulin with or without the GR antagonist RU486 $(10 \mu \mathrm{M})$, followed by insulin treatment every 3 days. As shown in Figure 1a, hMSCs differentiated into adipocytes and accumulated lipid droplets in the presence of AIM, but no obvious lipid accumulation was observed in hMSCs treated with RU486 during adipogenic stimulation. As the adipogenic process is characterized by expression of specific adipocyte markers such as $\mathrm{PPAR} \gamma, \mathrm{C} / \mathrm{EBP} \alpha$, and adiponectin, we next examined the expression of these adipocyte-specific genes by quantitave RT-PCR (Figure 1b). The expression of $\mathrm{PPAR} \gamma, \mathrm{C} / \mathrm{EBP} \alpha$, and adiponectin was increased in hMSCs incubated with adipogenic inducers for 2 days, and these gene expression levels were inhibited completely by RU486. These findings suggest that GR activity is necessary for the adipogenic differentiation of hMSCs.

We next examined whether the RU486 effect observed in hMSCs is similar in MEFs from wild-type mice. Wild-type
MEFs were differentiated into adipocytes, and RU486 inhibited the accumulation of lipid droplets albeit not as efficient as in hMSCs (Figure 1c). Expression of adipocytespecific marker genes in MEFs from wild-type mice were also inhibited by RU486 (Supplementary Figure 1). These data indicated that GR has a critical role in adipose differentiation from MEFs and hMSCs.

\section{Inhibition of Adipogenic Differentiation in MEFs from GR $^{\text {null }}$ and $\mathbf{G R}^{\text {dim }}$ Mice}

To further verify the role of GR in adipogenesis at the genetic level, we obtained MEFs from $\mathrm{GR}^{\text {null }}$ mice and observed that adipogenesis (Figure 2a; Supplementary Figure 2) and induction of marker gene expression was blocked in $\mathrm{GR}^{\text {null }}$ MEFs, as well as RU486 treatment (Figure $2 b$ and c). Furthermore, cells with a dimerization impaired GR $\left(\mathrm{GR}^{\mathrm{dim}}\right)$ failed to accumulate lipids and enhancement of adipocytemarker expression during adipogenic stimulation (Figure 2a-c). Taken together, these data clearly indicate that ligand-dependent GR transcriptional activity with its DNA binding to the target promoter is critical for adipogenesis.

\section{Screening for GR Targets in Adipogenesis by Microarray Expression Analysis}

To identify the genes regulated by GR during adipogenesis, total RNA was extracted from MEFs cultured with control medium, AIM, AIM with RU486, or Dex alone for 2 days; transcription was analyzed by microarray. As shown in Figure 3a, 1096 genes from AIM-treated cells that displayed at least a twofold expression change relative to control were selected as adipogenesis-specific genes; 203 genes from cells incubated with AIM and RU486 that displayed at least a twofold change compared with cells treated with AIM alone were selected as adipogenesis-RU486-regulated genes; and 1580 genes from Dex-treated cells that displayed at least a twofold change relative to control were selected as Dexregulated genes. Furthermore, after eliminating overlap and expressed sequence tags, 51 genes that belong to both the adipogenesis-RU486-regulated group and the Dex-regulated group were identified as GR-regulated adipogenic genes; a list of these 51 genes is displayed in Table 1. All 51 genes demonstrated an increase or decrease in expression with Dex treatment-45 genes were upregulated and 6 genes were downregulated during adipogenesis-and RU486 treatment had the opposite effect on their expression.

Figure 1 Effect of GR antagonist RU486 on adipogenesis in hMSCs and MEFs. hMSCs were differentiated into adipocytes with AIM (containing $500 \mu \mathrm{M} \mathrm{IBMX}$ $1 \mu \mathrm{M}$ Dex, $5 \mu \mathrm{g} / \mathrm{ml}$ insulin, $10 \mu \mathrm{M}$ pioglitazone) with or without $10 \mu \mathrm{M}$ RU486 for 3 days, followed by treatment with $5 \mu \mathrm{g} / \mathrm{ml}$ insulin alone for 3 days. These treatments were repeated. Cells were stained with Oil Red $\mathrm{O}$ at 12 days post-induction (a). Quantitative real-time PCR for the determination of expression levels adipogenic genes on day 2 after AIM exposure in the presence or absence of RU486 (b). MEFs were differentiated into adipocytes with AIM for 3 days, followed by treatment with insulin alone for 4 days. These treatments were repeated. Cells were stained with Oil Red $O$ at 14 days post-induction. Macroscopic (upper panel) and microscopic (lower panel) views are shown (c). Data from three independent experiments are mean \pm s.e.m.; $n=6$. $P$-values were determined by Steel-Dwass' test ( ${ }^{*} P<0.05$ vs control, ${ }^{*} P<0.05$ vs AIM). 


\section{Candidates for GR Direct Target Genes in MEF During Adipogenesis}

To reveal transcriptional network in adipogenesis, we focused on transcription factors, which were induced as GR direct target genes in adipogenesis. Among the 45 genes showing adipogenesis and GR-dependent upregulation in Table 1, 5 genes are transcriptional factors: Zbtb16 (zinc finger and BTB domain containing 16), HIF3 $\alpha$ (hypoxia-inducible factor 3 , a

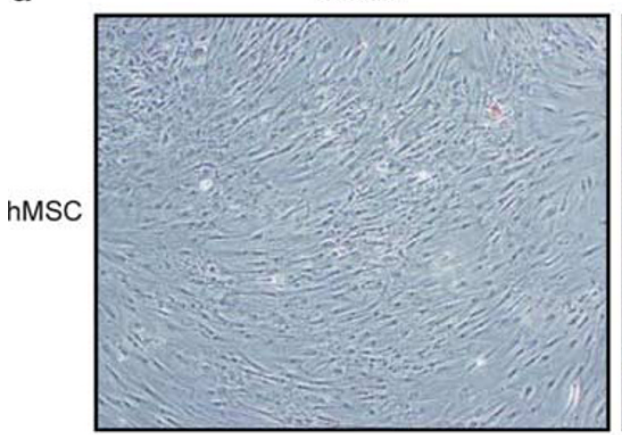

AIM

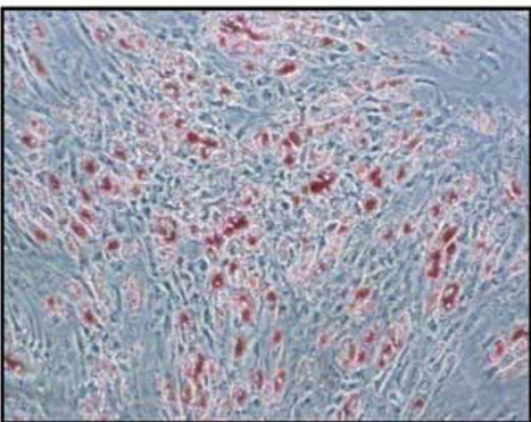

$A I M+R U$

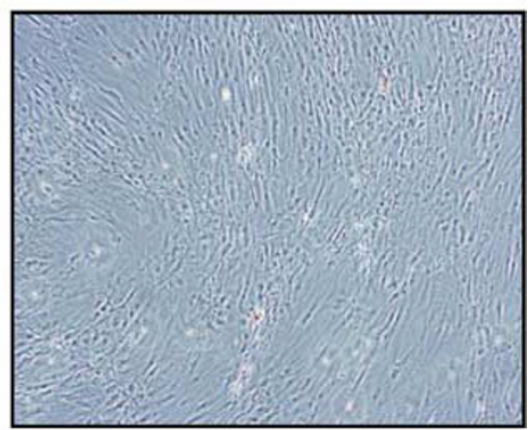

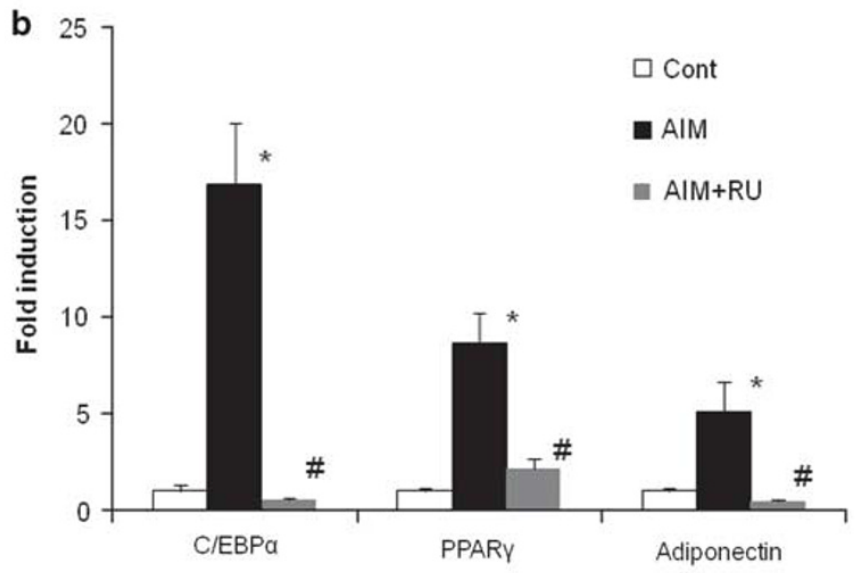

C Control AIM $\mathrm{AIM}+\mathrm{RU}$

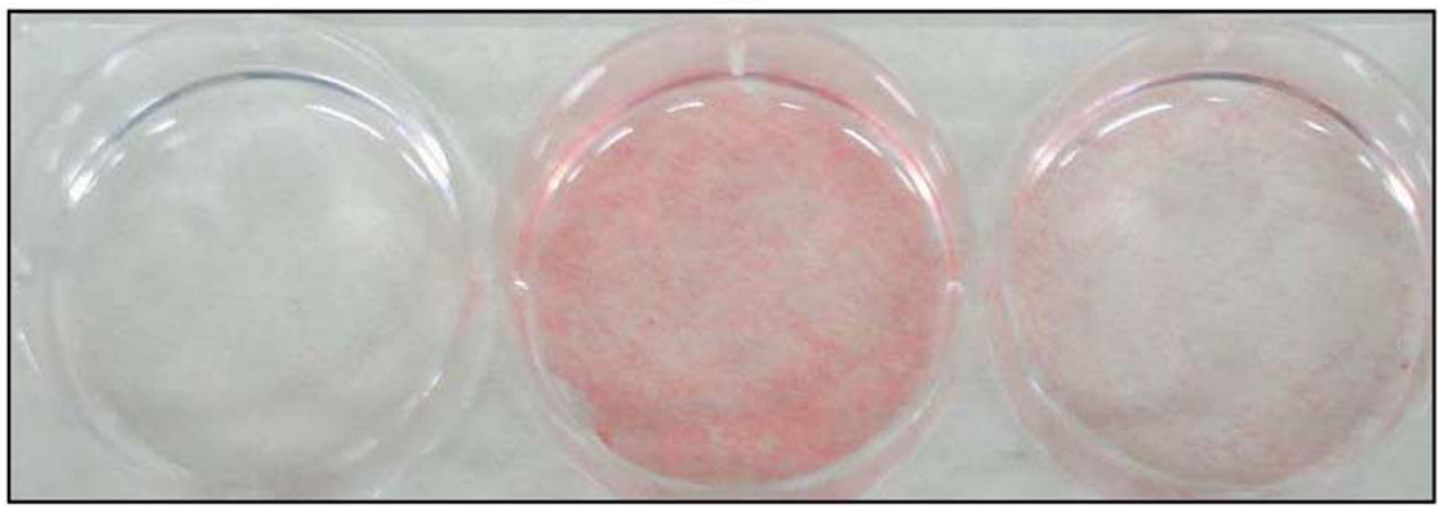

MEFs
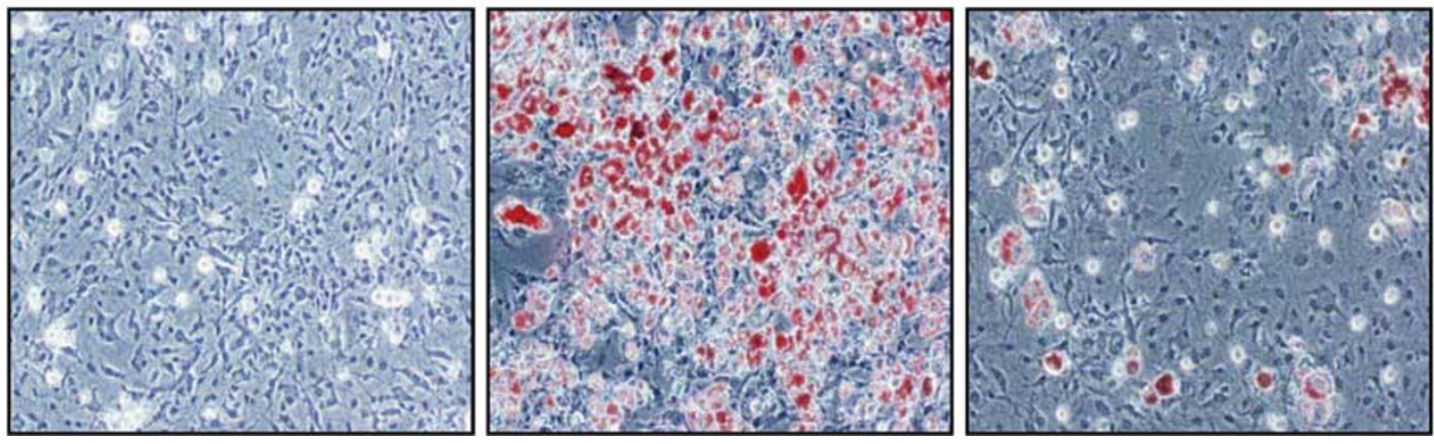
a
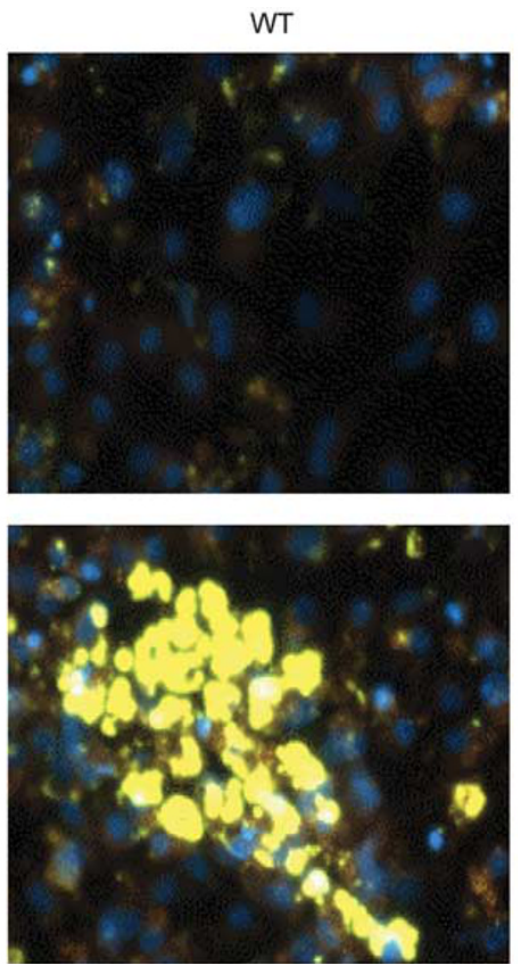

$\mathrm{GR}^{\text {null }}$
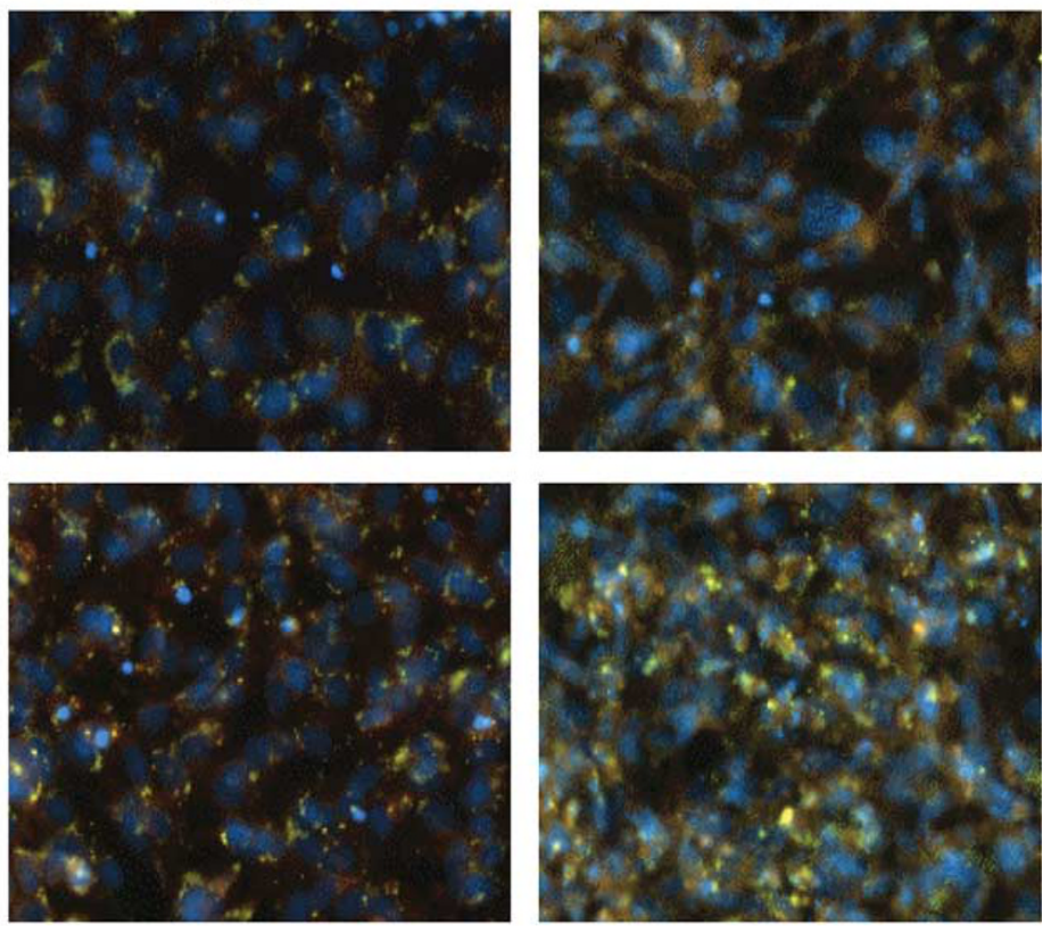

b

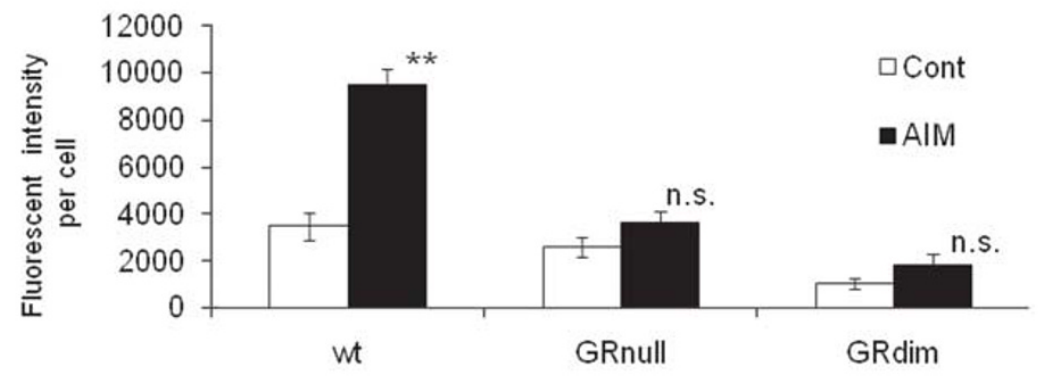

C
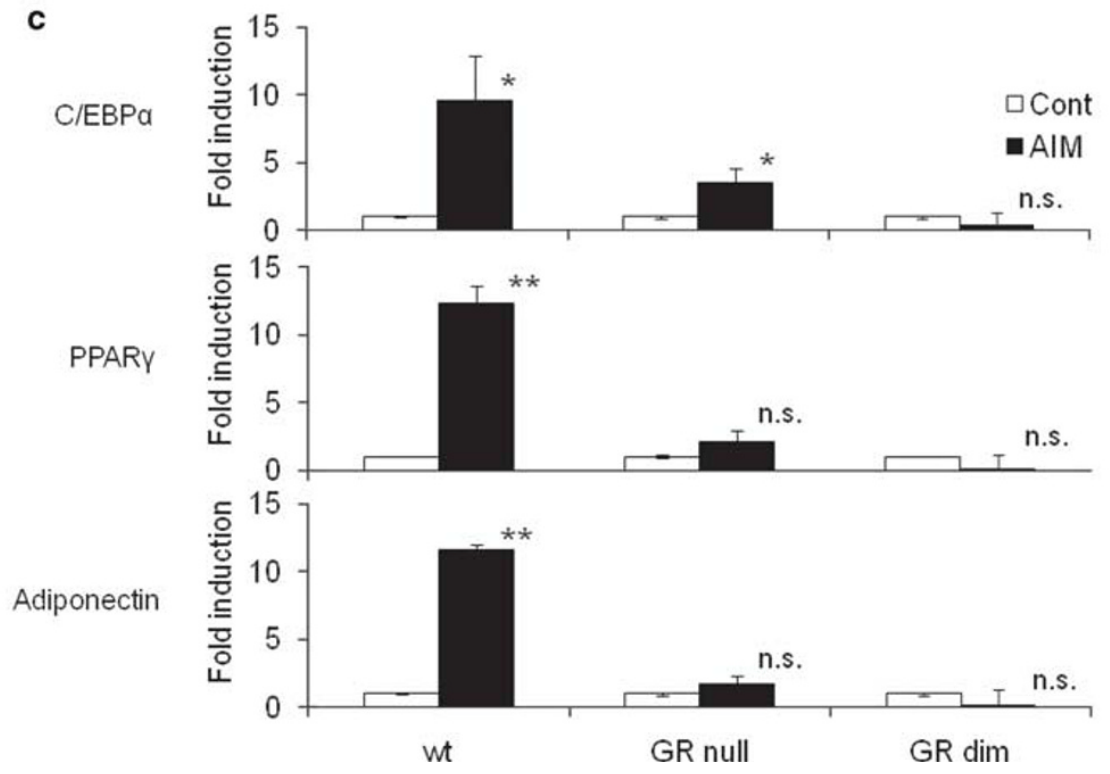
$\alpha$ subunit), Zhx3 (zinc fingers and homeoboxes 3), KLF9 (Krüppel-like factor 9), and KLF15.

Expression of these five genes was confirmed by real-time RT-PCR using cDNA from MEFs at day 2 after adipogenic induction \pm RU486 or with Dex alone (Figure 3b). Expression of Zbtb16 (also known as ZFP145 or PLZF) was strongly induced by Dex; consistent with a previous report showing that glucocorticoids regulate Zbtb16 gene expression via the promoter region of this gene, ${ }^{38}$ and so far there is no report on the roles of Zbtb16, HIF3 $\alpha$, Zhx3, or KLF9 in adipogenesis. KLF15 has been reported to be induced by Dex and IBMX ${ }^{28,39}$ and act as an adipogenic inducer via PPAR $\gamma$ a

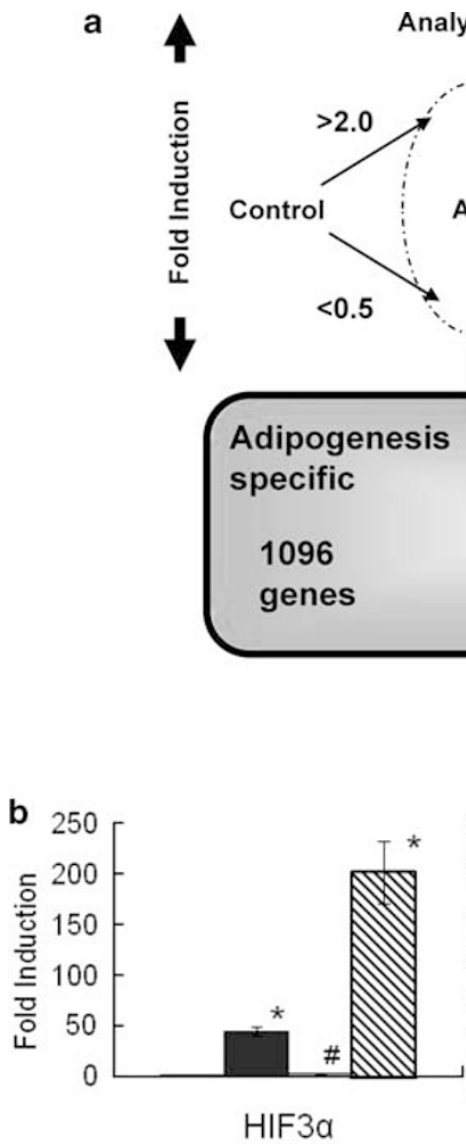

Analysis A<smiles>CCCCC</smiles>

AIM

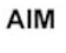

<

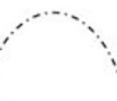

Analysis B

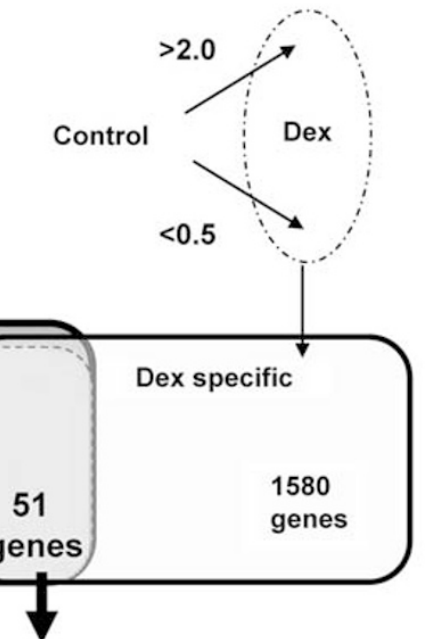

GR-regulated adipogenic genes

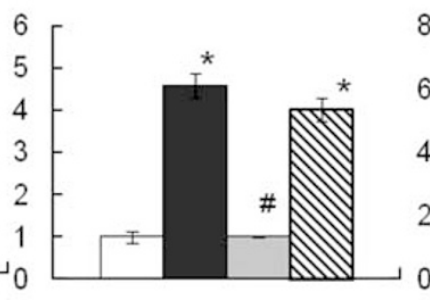

KLF9

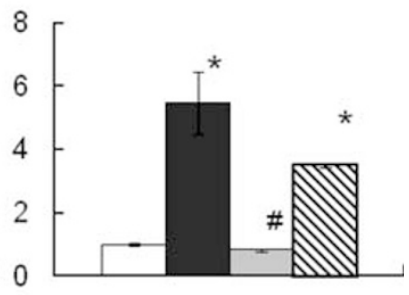

KLF15

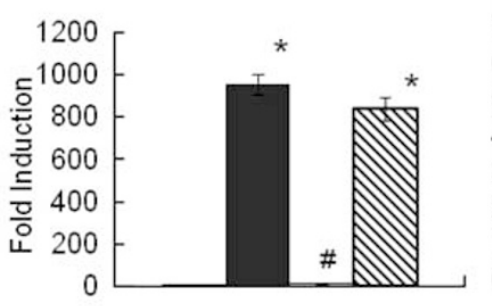

Zbtb 16

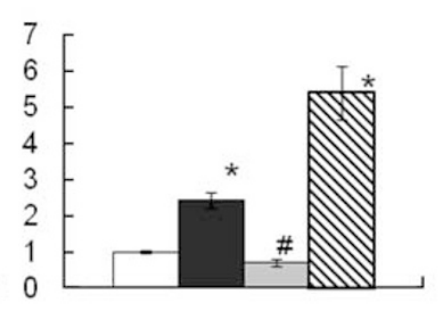

Zhx 3

$\square$ Cont

aIM

$\square \mathrm{AIM}+\mathrm{RU}$

$\Delta \operatorname{Dex}$

Figure 3 Screening for GR-regulated adipogenic-induced genes by microarray expression analysis. Scheme of microarray data analysis showing genes with increased or decreased expression in each treatment group (a). Genes with signal intensities below 50 were eliminated and normalized, and then genes from cells incubated with AIM or Dex treatment that exhibited at least a twofold change relative to the control treatment were selected for analysis. Expression profiles for GR-regulated adipogenic genes in MEF were confirmed with quantitative RT-PCR in Control, AIM, AIM + RU, and Dex treatment groups on day 2 (b). Data are mean \pm s.e.m.; $n=4$. $P$-values were determined by Steel-Dwass' test $\left({ }^{*} P<0.05\right.$ vs control, ${ }^{\#} P<0.05$ vs AIM).

Figure 2 Induction of adipocyte differentiation in MEFs from $G R^{\text {dim }}$ and $G R^{\text {null }}$ mice. MEFs derived from wild type, $G R^{\text {null }}$ and $G R^{\text {dim }}$ mice were differentiated into adipocytes and stained with Nile Red for lipid droplets (yellow) and DAPI (blue) (a). Total fluorescent intensity of lipid droplets per cell were analyzed by

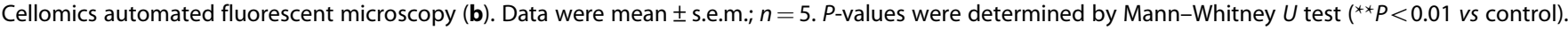
Analysis of mRNA expression of adipogenesis-specific factors in wild type, GR ${ }^{\text {dim }}$ and GR ${ }^{\text {null }}$ MEFs during adipogenesis using quantitative RT-PCR 1 day after adipogenic differentiation (c). Data are mean \pm s.e.m.; $n=3$. $P$-values were determined by Mann-Whitney $U$ test ( ${ }^{* * P}<0.01$ vs control, ${ }^{\star} P<0.05$ vs control). 
Table 1 Microarray analysis of GR-regulated adipogenic genes

\begin{tabular}{|c|c|c|c|c|}
\hline \multicolumn{3}{|c|}{ Fold induction } & \multirow[t]{2}{*}{ Symbol } & \multirow[t]{2}{*}{ Description } \\
\hline AIM & $\mathrm{AIM}+\mathrm{RU}$ & Dex & & \\
\hline 367.2 & 19.0 & 249.9 & Zbtb16 & Zinc finger and BTB domain containing 16 \\
\hline 144.1 & 55.2 & 39.8 & Serpina3c & Serine (or cysteine) proteinase inhibitor, clade $\mathrm{A}$, member $3 \mathrm{C}$ \\
\hline 78.0 & 15.8 & 39.2 & $\mathrm{Hp}$ & Haptoglobin \\
\hline 70.5 & 16.0 & 14.8 & Serpina3m & Serine (or cysteine) proteinase inhibitor, clade A, member 3M \\
\hline 36.2 & 15.5 & 3.8 & Prg4 & Proteoglycan 4 (megakaryocyte-stimulating factor, articular superficial zone protein) \\
\hline 23.6 & 0.9 & 11.3 & Hif3a & Hypoxia-inducible factor $3, \alpha$ subunit \\
\hline 23.4 & 1.6 & 22.6 & BC055107 & cDNA sequence $\mathrm{BC} 055107$ \\
\hline 22.8 & 8.1 & 7.3 & Fabp4 & Fatty acid binding protein 4 , adipocyte \\
\hline 20.1 & 2.3 & 8.6 & Dpep1 & Dipeptidase 1 (renal) \\
\hline 19.7 & 2.3 & 9.6 & Fkbp5 & FK506 binding protein 5 \\
\hline 19.6 & 7.3 & 21.6 & $\mathrm{Cp}$ & Ceruloplasmin \\
\hline 15.6 & 3.3 & 3.7 & 5430433G21Rik & RIKEN cDNA 5430433G21 gene \\
\hline 13.5 & 2.3 & 9.8 & Aldh1a7 & Aldehyde dehydrogenase family 1 , subfamily $A 7$ \\
\hline 11.7 & 3.6 & 4.4 & B230114P17Rik & RIKEN cDNA B230114P17 gene \\
\hline 11.2 & 4.1 & 10.0 & Al607873 & Expressed sequence Al607873 \\
\hline 9.9 & 0.7 & 9.9 & Fmo3 & Flavin-containing monooxygenase 3 \\
\hline 8.8 & 3.9 & 2.1 & $\mathrm{Cd} 24 \mathrm{a}$ & CD24a antigen \\
\hline 8.0 & 0.2 & 6.0 & Fmo2 & Flavin-containing monooxygenase 2 \\
\hline 7.9 & 2.0 & 3.6 & 1300002F13Rik & RIKEN cDNA $1300002 F 13$ gene \\
\hline 7.6 & 3.4 & 8.1 & Ms4a4d & Membrane-spanning 4-domains, subfamily A, member 4D \\
\hline 7.5 & 2.4 & 2.9 & Glul & Glutamate-ammonia ligase (glutamine synthase) \\
\hline 6.4 & 1.0 & 3.9 & $\operatorname{Tsc} 22 \mathrm{~d} 3$ & TSC22 domain family 3 \\
\hline 5.6 & 0.9 & 6.4 & Pdk4 & Pyruvate dehydrogenase kinase, isoenzyme 4 \\
\hline 4.6 & 1.5 & 2.1 & Ms4a6b & Membrane-spanning 4-domains, subfamily A, member 6B \\
\hline 4.5 & 2.1 & 2.6 & LOC553901 & Hypothetical LOC553901 \\
\hline 4.4 & 1.1 & 3.2 & Ndrg2 & $\mathrm{N}$-myc downstream regulated gene 2 \\
\hline 4.3 & 2.1 & 3.0 & Rgs2 & Regulator of G-protein signaling 2 \\
\hline 4.3 & 1.1 & 6.4 & Sult1a1 & Sulfotransferase family $1 \mathrm{~A}$, phenol preferring, member 1 \\
\hline 4.1 & 1.9 & 3.4 & Gm368 & Gene model 368 (NCBI) \\
\hline 3.8 & 1.8 & 2.1 & Zhx3 & Zinc fingers and homeoboxes 3 \\
\hline 3.7 & 1.4 & 2.1 & KIf9 & Kruppel-like factor 9 \\
\hline 3.5 & 1.7 & 4.1 & Clca1///Clca2 & Chloride channel calcium-activated 1///chloride channel calcium-activated 2 \\
\hline 3.5 & 1.6 & 2.2 & Admr & Adrenomedullin receptor \\
\hline 3.5 & 1.7 & 3.5 & 2310005P05Rik & RIKEN cDNA 2310005P05 gene \\
\hline 3.4 & 1.1 & 2.8 & Crispld2 & Cysteine-rich secretory protein LCCL domain containing 2 \\
\hline 3.1 & 1.5 & 2.2 & Klf15 & Kruppel-like factor 15 \\
\hline 3.1 & 0.9 & 4.3 & Ctla2b & Cytotoxic T lymphocyte-associated protein $2 \beta$ \\
\hline 3.0 & 0.7 & 2.4 & Stc2 & Stanniocalcin 2 \\
\hline 3.0 & 1.1 & 2.8 & Aldh1a1 & Aldehyde dehydrogenase family 1 , subfamily A1 \\
\hline 2.8 & 1.1 & 2.7 & 1810049K24Rik & Cysteine-rich secretory protein LCCL domain containing 2 \\
\hline 2.4 & 1.1 & 2.3 & $\operatorname{Sen} 7 \mathrm{a}$ & Sodium channel, voltage-gated, type VII, $\alpha$ \\
\hline 2.4 & 1.1 & 2.4 & Rab3d & RAB3D, member RAS oncogene family \\
\hline 2.2 & 0.8 & 2.3 & Prkar2b & Protein kinase, cAMP-dependent regulatory, type ॥ $\beta$ \\
\hline 2.2 & 0.9 & 3.7 & Clec1a & C-type lectin domain family 1 , member a \\
\hline 2.1 & 1.0 & 2.3 & Sgk & Serum/glucocorticoid-regulated kinase \\
\hline 0.4 & 0.9 & 0.4 & 4632408A20Rik & RIKEN cDNA 4632408A20 gene \\
\hline 0.3 & 1.0 & 0.4 & Sec15l1 & SEC15-like 1 (S. cerevisiae) \\
\hline 0.3 & 0.7 & 0.5 & 1810057P16Rik & RIKEN cDNA 1810057 P16 gene \\
\hline 0.2 & 0.5 & 0.5 & Slc7a5 & Solute carrier family 7 (cationic amino-acid transporter, y+ system), member 5 \\
\hline 0.2 & 0.4 & 0.5 & E030004N02Rik & RIKEN cDNA E030004N02 gene \\
\hline 0.1 & 0.3 & 0.5 & Gucy1a3 & Guanylate cyclase 1 , soluble, $\alpha 3$ \\
\hline
\end{tabular}



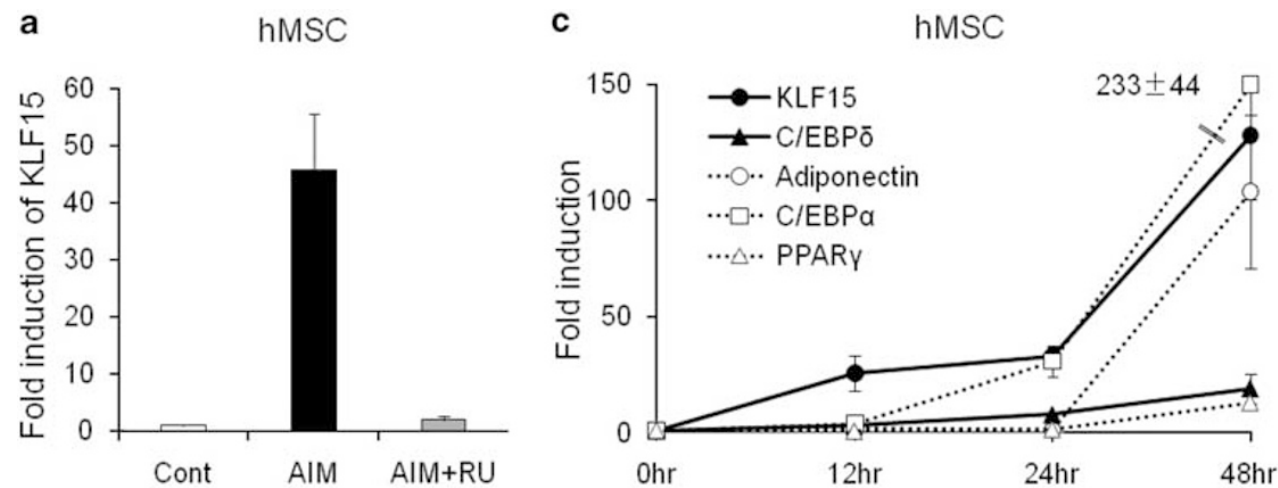

b
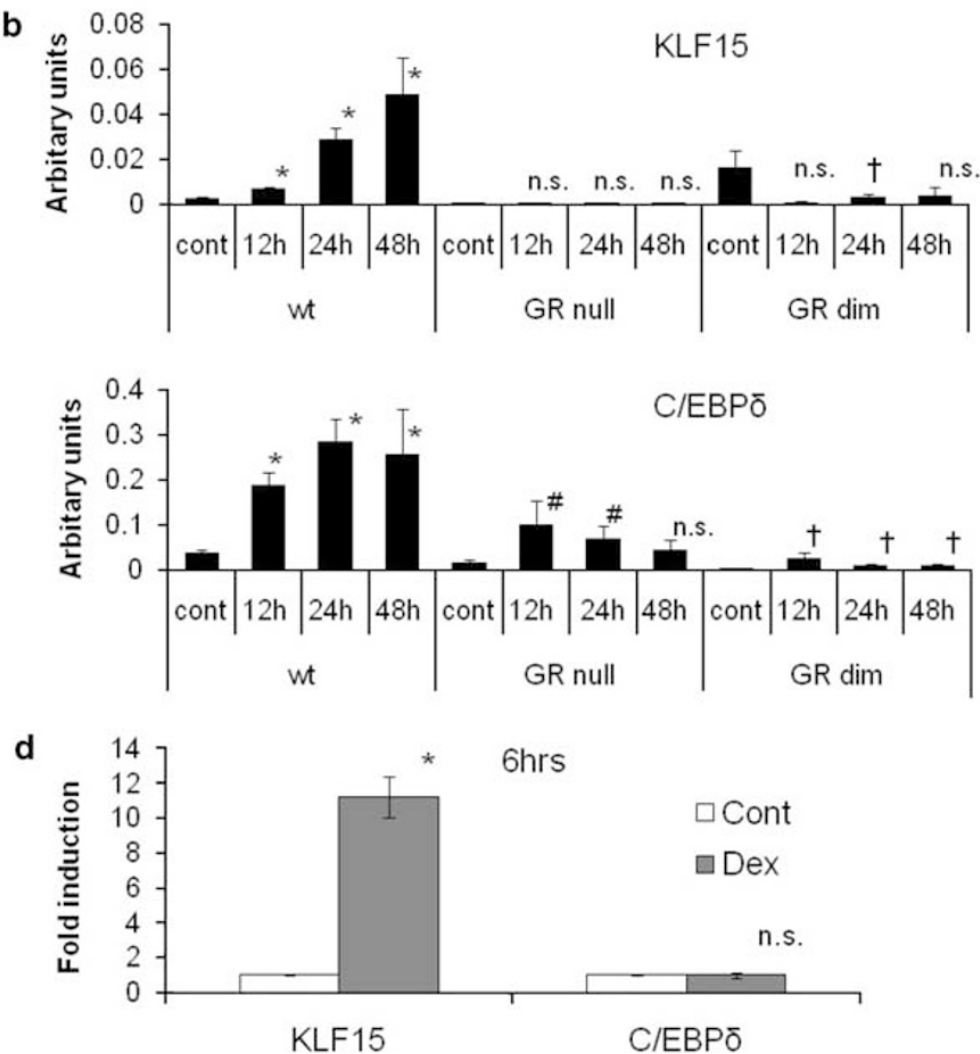

Figure 4 Expressions of KLF15 and C/EBP $\delta$ mRNA in MEFs from wild type, GR ${ }^{\text {dim }}$ and GR ${ }^{\text {null }}$ mice. Expression of KLF15 and effect of RU486 for KLF15 in hMSCs 2 days after induction (a) and expression of KLF15 and C/EBP $\delta$ in wild type, GR ${ }^{\text {dim }}$ and GR ${ }^{\text {null }}$ MEFs during adipogenesis (b). Data are mean \pm s.e.m.; $n=3$. Data were statistically analyzed with Steel's test $\left({ }^{*} P<0.05\right.$ vs wild type $0 \mathrm{~h},{ }^{\#} P<0.05$ vs $\mathrm{GR}^{\text {null }} 0 \mathrm{~h}{ }^{\dagger} P<0.05$ vs $\mathrm{GR}^{\text {dim }} 0 \mathrm{~h}$ ). Time courses of expression of KLF15 and adipogenic-marker genes in hMSCs (c). Expressions of KLF15 and C/EBP $\delta$ in wild-type MEFs at $6 \mathrm{~h}$ after Dex alone stimulation (d). Total RNA was analyzed using quantitative RT-PCR. Data are mean \pm s.e.m.; $n=3-4$. $P$-values were determined by Mann-Whitney $U$ test ( ${ }^{\star} P<0.05$ vs control).

induction; ${ }^{30,39}$ however, the molecular relationship between GR-dependent transcription and KLF15 expression is largely unrevealed yet.

\section{KLF15 Expression Is Dependent on GR Dimerization}

Consistent with the above observation, KLF15 expression was increased during adipose differentiation in both hMSCs and wild-type MEFs, and this induction was inhibited by RU486, suggesting the critical role of GR in KLF15 gene expression in adipogenesis (Figures $3 \mathrm{~b}$ and $4 \mathrm{a}$ ). To examine whether induction of KLF15 during adipogenesis is directly regulated by GR or not, we tested the expression of KLF15 using GR ${ }^{\text {null }}$ and $\mathrm{GR}^{\mathrm{dim}}$ MEFs and found that KLF15 gene expression during adipogenesis was inhibited (Figure 4b). These data suggest that KLF15 expression during adipogenesis needs ligand-dependent and DNA binding-dependent GR transcriptional activity.

Interestingly, $\mathrm{C} / \mathrm{EBP} \delta$ expression was induced with AIM although basic expression was decreased in both $\mathrm{GR}^{\text {null }}$ and $\mathrm{GR}^{\mathrm{dim}}$ MEFs (fold induction: $4.97 \pm 0.98$ in wild type, $6.38 \pm 3.33$ in $\mathrm{GR}^{\text {null }} 7.91 \pm 3.41$ in $\mathrm{GR}^{\mathrm{dim}}$ at $12 \mathrm{~h}$ ) (Figure $4 \mathrm{~b}$ ). Kinetics analysis of gene expression showed 


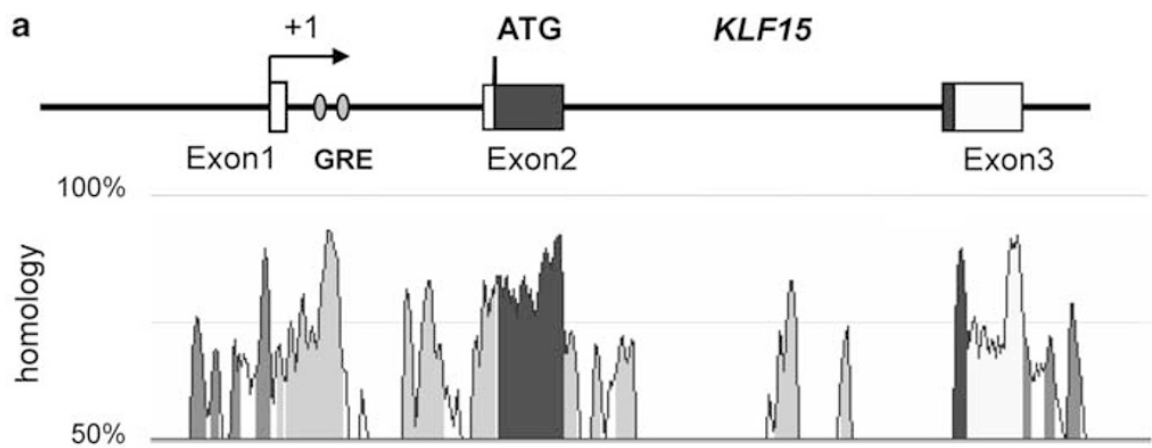

b

$$
\begin{aligned}
& \text { mKLF15 GRE1 gttatcaattacatgttgttcctacagCC }+980-+998 \\
& \text { hKLF15 GRE1 gttatcaattacatgttgttcctgcagCC } \\
& \text { mKLF15 GRE2 } \\
& \text { hKLF15 GRE2 }
\end{aligned}
$$

C

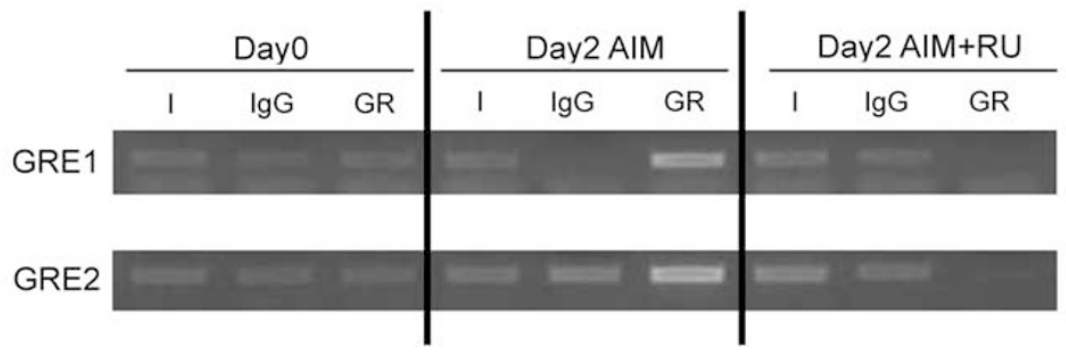

Figure 5 GRE sites in the KLF15 gene first intron. The highly conserved region between human and mouse in the KLF15 first intron (a). GRE site sequence in the first intron of KLF15 (b). The conserved region between human and mouse genomes was identified by rVista 2.0 and the homology graph from the ECR browser, and putative GRE sites were discovered with MatInspector. Chromatin immunoprecipitation was performed in MEFs differentiated with AIM for 2 days. DNA immunoprecipitated with anti-GR antibodies from treated cells was used to amplify the nucleotide sequences located between +933 to +1070 bp (GRE1), and + 1055 to +1216 bp (GRE2) in the KLF15 first intron (c). I, input; lgG, normal rabbit serum IgG.

KLF15 expression is induced earlier than C/EBP $\delta$ expression in MSCs and MEFs (Figure 4c; Supplementary Figure 3). Consistent with these findings, Dex treatment strongly and promptly induced KLF15 gene expression, but not C/EBP $\delta$ gene expression (Figure 4d). These data suggest that the ligand-bound GR is critical for promoting KLF15 in adipogenesis and that $\mathrm{C} / \mathrm{EBP} \delta$ in adipogenesis can be alternatively induced by other factors (eg IBMX) without GR.

\section{GR Directly Binds to GRE Sites in the First Intron of KLF15}

Using bioinformatics, we analyzed the promoter regionsKLF15 (7500 to +2000 bp). A conserved region between human and mouse KLF15 promoters was identified in the first intron by rVista 2.0; two putative GRE sites (GRE1 and GRE2) were identified by analysis with MatInspector (Figure $5 \mathrm{a}$ and $\mathrm{b}$ ).

To confirm these findings, we used the ChIP assay to determine whether GR binds to GRE sites in the first intron of KLF15 during adipocyte differentiation. Chromatin samples were prepared from MEFs undergoing adipogenic differentiation with or without RU486, then immunoprecipitated with a specific antibody against GR. GR was found to be associated with both GRE1 and GRE2 in a conserved region of KLF15, and this association was inhibited by RU486 (Figure 5c). These results confirmed that GR directly binds to GRE sites in the first intron of KLF15 during adipogenesis.

\section{GR Induces Promoter Activity via KLF15 First Intron}

To define the mechanism by which GR induces KLF15 expression, we performed transient transfection studies in 293T cells using reporter constructs of the KLF15 intron ( +933 to +1216 ), including two GRE sites under the HSV TK promoter (Figure 6a). Dex treatment resulted in an approximate 10 -fold induction of expression of the KLF15 promoter, and this induction was inhibited by RU486 treatment (Figure 6b).

To determine which potential GR-binding site in the first intron of KLF15 was involved in transactivation, we introduced point mutations at the GRE 1 site (ATTAC ATGTTGTTCC $\rightarrow$ ACAACATGTTCATCC) and at the GRE2 site (AGAACAGGGTGCCCC $\rightarrow$ ACAACAGGGTCACCC). Both mutations in the GRE1 or GRE2 resulted in a loss of transactivation (Figure 6c). Moreover, introduction of mutations at both GRE1 and GRE2 caused an even greater 
a

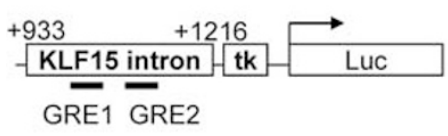

b

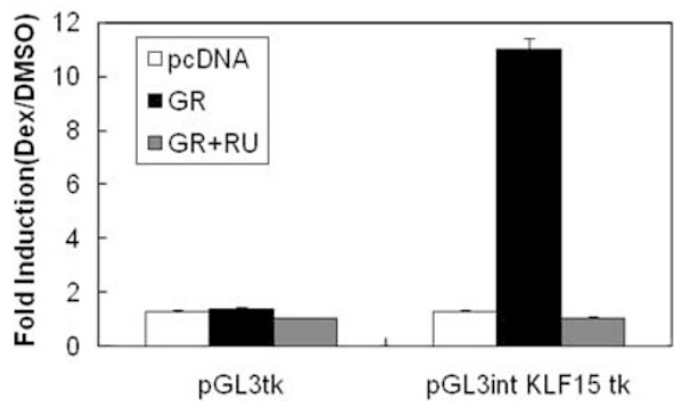

c

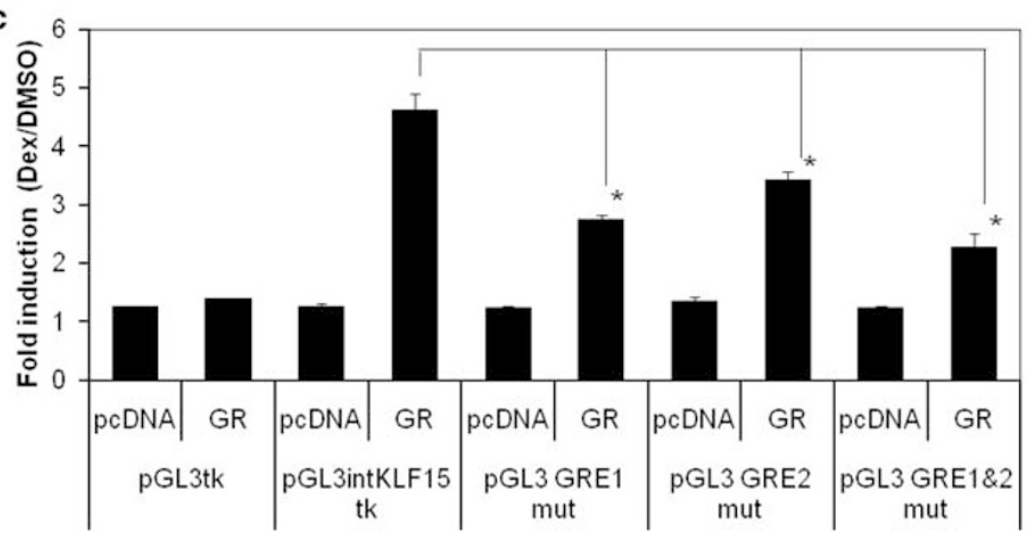

Figure 6 Promoter activity of reporter constructs containing +933 to +1216 bp of the KLF15 first intron. Map of pGL3 intKLF15 tk reporter vector (a). 293T cells were transiently transfected with the reporter construct pGL3-intKLF15-tk (b) or deletion constructs pGL3-GRE1mut (GRE1 mutation), pGL3-GRE2mut (GRE2 mutation), pGL3-GRE1\&2mut (GRE1 and GRE2 mutations) (c), and empty vector (pcDNA) or GR expression vector. After 24h, cells were incubated in Dex $(100 \mathrm{nM})$ or DMSO (vehicle) with or without $10 \mu \mathrm{M}$ RU486 for $24 \mathrm{~h}$ before the luciferase assay. Results were expressed as fold induction compared with cells treated with DMSO alone. Data are expressed as the mean \pm s.d. of triplicates from representative experiments. Results were evaluated by Steel's test ( ${ }^{*} P<0.05$ vs pGL3-intKLF15-tk with Dex).

reduction in transactivation. These data suggest that GR can transactivate the KLF15 promoter activity by binding these GRE consensus sites.

\section{Knockdown of KLF15 Inhibited Adipogenesis}

Finally, to investigate the function of KLF15 on adipogenesis, we examined the effect of siKLF15 during adipogenic differentiation in MEFs. As shown in Figure 7a, MEFs transfected with nonspecific siRNA (siNega) differentiated into adipocytes and accumulated lipid droplets, but less lipid accumulation was observed in MEFs transfected with siKLF15 during adipogenic stimulation. We examined the expression of adipocyte-specific genes by quantitative RT-PCR 2 days after stimulation (Figure 7b). KLF15 gene expression was inhibited by siKLF15 and adipocyte-marker genes, $\mathrm{C} / \mathrm{EBP} \alpha$ and $\mathrm{PPAR} \gamma$ were reduced whereas adiponectin was not affected. Thus, KLF15 induction contributes to adipocyte differentiation.

\section{DISCUSSION}

In this study, we used the GR antagonist RU486 and GRmutant mice to provide evidence for an essential role for GR in adipogenesis. The GR and in particular its dimerization function are essential for in vitro adipogenesis, as cells with a
GR impaired in dimerized DNA binding derived from $\mathrm{GR}^{\mathrm{dim}}$ mice fail to differentiate into adipocytes. Thus, genes under the control of GR-DNA interaction, which comprise a subset of GR-regulated genes are involved in adipogenesis. ${ }^{40}$ The KLF15 gene was identified as a direct GR target in MEF during adipogenesis, and KLF15 has the critical role in adipogenic differentiation. Previous studies showed that KLF15 is induced by ectopic expression of $\mathrm{C} / \mathrm{EBP} \delta$ and $\mathrm{C} / \mathrm{EBP} \beta$, and Dex and IBMX stimulation in 3T3-L1 cells. ${ }^{28}$ Our data showed that KLF15 is more rapidly induced than C/EBP $\delta$ mRNA, suggesting a C/EBP $\delta$ - independent pathway for GRmediated KLF15 induction (Figure 8).

KLF15 is expressed in major tissues such as liver, kidney, heart, skeletal muscle, and adipose tissue. $\mathrm{KLF}^{-1-}$ mice display severe hypoglycemia, with a deficiency in amino-acid metabolic enzymes in the liver and muscle. ${ }^{30}$ These findings raise the question of the function of adipose tissue in these mice. GR has an important role in glucose and amino-acid homeostasis in liver, muscle, and adipose tissue during gluconeogenesis under fasting conditions. ${ }^{30}$ Fasting increases endogenous glucocorticoids, and induces gluconeogenesisassociated genes, such as PEPCK and G6Pase in the liver ${ }^{41}$; liver-specific GR-deficient mice displayed hypoglycemia while fasting, similar to $\mathrm{KLF}^{-1} 5^{-1}$ mice. Expression of KLF15 is 

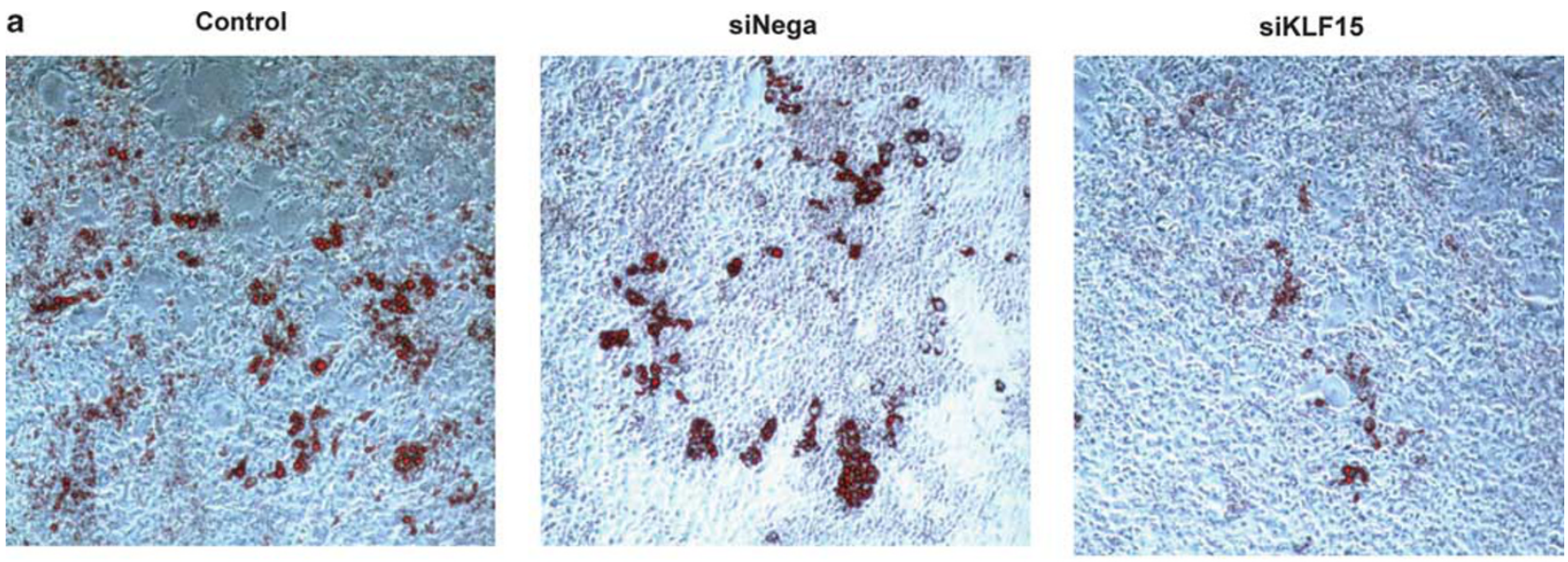

b
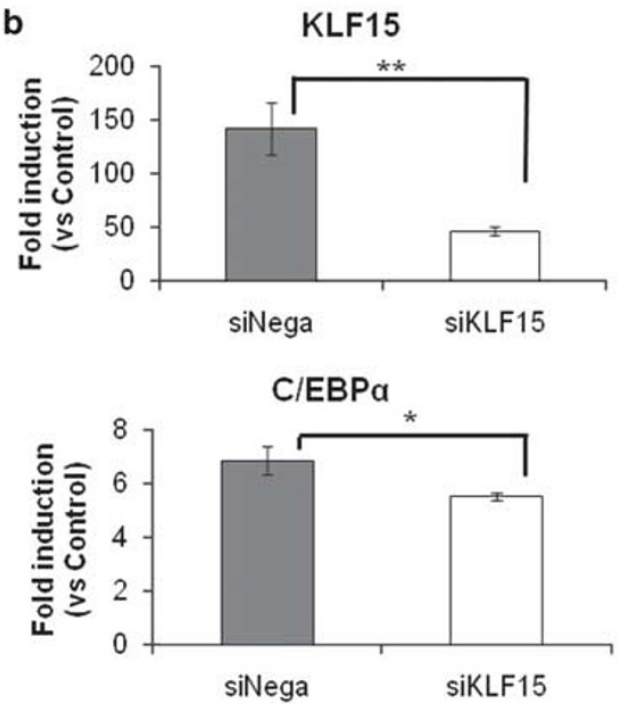
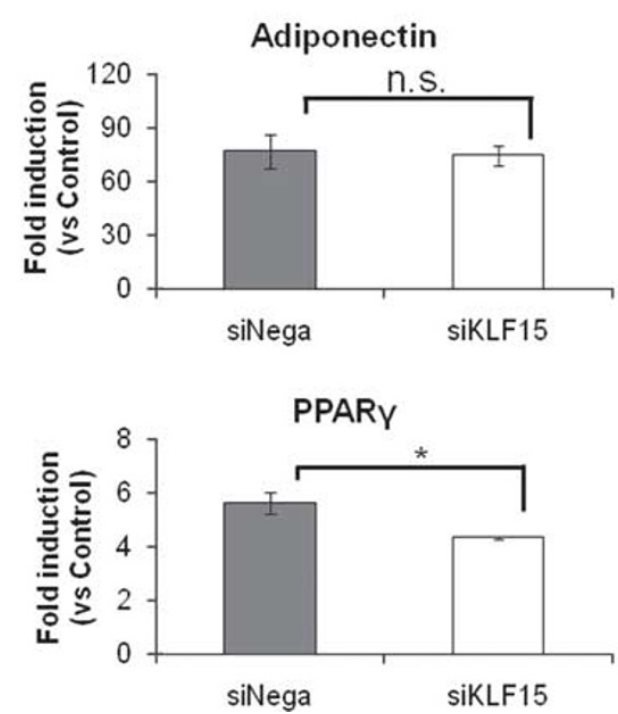

Figure 7 Effect of KLF15 knockdown on adipogenesis in MEFs. 50 nM siRNA for KLF15 (siKLF15) and 50 nM nonspecific siRNA (siNega) were transfected into MEFs. After $48 \mathrm{~h}$, cells were differentiated into adipocytes in the same way as wild-type MEFs Figure 1 and were stained with Oil Red $\mathrm{O}$ at 14 days postinduction (a). Expression of KLF15 and adipogenic-specific marker genes in siRNA-transfected MEFs (b). Total RNA was extracted from cells 2 days after initiating adipose differentiation and analyzed using quantitative RT-PCR. Data are mean \pm s.e.m.; $n=6-10$. $P$-values were determined by Mann-Whitney $U$ test $\left({ }^{*} P<0.01\right.$ vs siNega, ${ }^{*} P<0.05$ vs siNega).

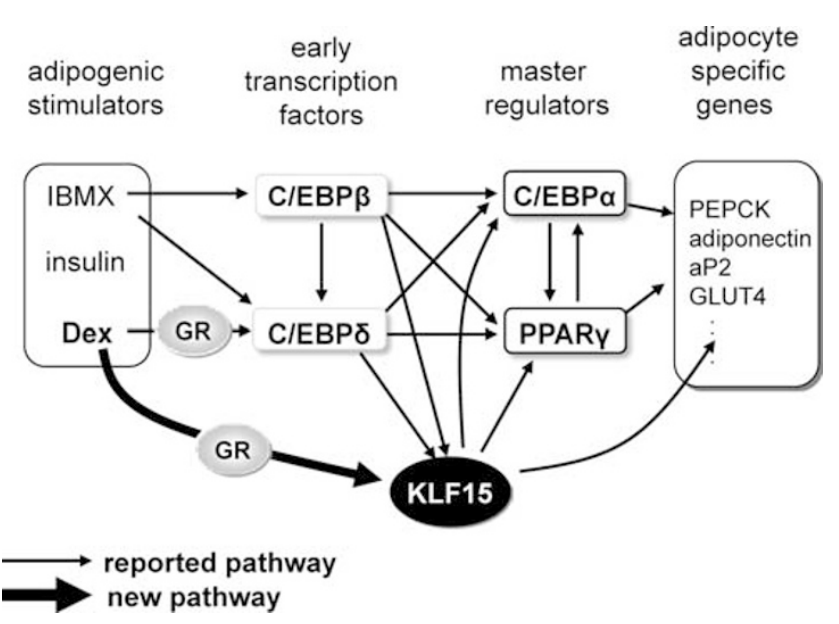

Figure 8 Schematic model of the pathways controlling differentiation. GR directly regulates KLF15 expression, which acts as an adipocyte differentiation activator at the transcriptional level in hMSCs and MEFs. increased in the liver, ${ }^{42}$ muscle, ${ }^{43}$ and adipocytes in fasting conditions (data not shown). These findings suggest that the glucocorticoid effects may be partially mediated by KLF15 in vivo.

In $\mathrm{GR}^{\text {null }}$ mice or $\mathrm{GR}^{\mathrm{dim}}$ mice, developments of white adipose tissues in embryos are normal comparative to wild type under normal conditions (data not shown); however, various stresses, such as a high-fat diet, may reveal the functions of GR in adipogenesis in vivo.

Further in vitro and in vivo studies to investigate the expression of the adipogenic regulators and GR-target genes (KLF15, etc) using $\mathrm{GR}^{\text {null }}$ embryos and $\mathrm{GR}^{\mathrm{dim}}$ mice will generate a clearer picture of the roles of GR during adipocyte differentiation. Excessive glucocorticoids cause ectopic adipose distribution (central obesity, buffalo hump, etc) and contribute to metabolic disease through the facilitation of adipose tissue expansion. Our findings in this study will allow a more focused approach toward studying the 
mechanisms underlying the effect of glucocorticoids on adipose tissue in vivo.

Supplementary Information accompanies the paper on the Laboratory Investigation website (http://www.laboratoryinvestigation.org)

\section{ACKNOWLEDGEMENTS}

This study was supported by NIH grants AR-50631, AR-56120, the Arthritis National Research Foundation, Grants from the Genome Network Project (MEXT), Grants-in Aid for Scientific Research (MEXT), Labour Sciences Research Grants, Research on Child Health and Development, Grant ID10-43 from the National Institute of Biomedical Innovation, The Japan Health Sciences Foundation and the Boehringer Ingelheim Stiftung (to JT).

\section{DISCLOSURE/CONFLICT OF INTEREST}

The authors declare no conflict of interest.

1. Green $H$, Kehinde $O$. An established preadipose cell line and its differentiation in culture. II. Factors affecting the adipose conversion. Cell 1975;5:19-27.

2. Green $\mathrm{H}$, Kehinde $\mathrm{O}$. Spontaneous heritable changes leading to increased adipose conversion in 3T3 cells. Cell 1976;7:105-113.

3. Rosen OM, Smith CJ, Fung C, et al. Development of hormone receptors and hormone responsiveness in vitro. Effect of prolonged insulin treatment on hexose uptake in 3T3-L1 adipocytes. J Biol Chem 1978:253:7579-7583.

4. Rubin CS, Hirsch A, Fung C, et al. Development of hormone receptors and hormonal responsiveness in vitro. Insulin receptors and insulin sensitivity in the preadipocyte and adipocyte forms of 3T3-L1 cells. J Biol Chem 1978;253:7570-7578.

5. Gregoire FM, Smas CM, Sul HS. Understanding adipocyte differentiation. Physiol Rev 1998;78:783-809.

6. Rosen ED, Walkey $\mathrm{CJ}$, Puigserver $\mathrm{P}$, et al. Transcriptional regulation of adipogenesis. Genes Dev 2000;14:1293-1307.

7. Farmer SR. Transcriptional control of adipocyte formation. Cell Metab 2006;4:263-273.

8. Rosen ED, Hsu CH, Wang $\mathrm{X}$, et al. C/EBPalpha induces adipogenesis through PPARgamma: a unified pathway. Genes Dev 2002;16:22-26.

9. Rosen ED, Sarraf $P$, Troy $A E$, et al. PPAR gamma is required for the differentiation of adipose tissue in vivo and in vitro. Mol Cell 1999;4:611-617.

10. Tontonoz $\mathrm{P}, \mathrm{Hu}$ E, Spiegelman BM. Stimulation of adipogenesis in fibroblasts by PPAR gamma 2, a lipid-activated transcription factor. Cell 1994;79:1147-1156.

11. Cao Z, Umek RM, McKnight SL. Regulated expression of three C/EBP isoforms during adipose conversion of 3T3-L1 cells. Genes Dev 1991;5:1538-1552.

12. Wu Z, Bucher NL, Farmer SR. Induction of peroxisome proliferatoractivated receptor gamma during the conversion of $3 \mathrm{~T} 3$ fibroblasts into adipocytes is mediated by C/EBPbeta, C/EBPdelta, and glucocorticoids. Mol Cell Biol 1996;16:4128-4136.

13. Yeh WC, Cao Z, Classon $M$, et al. Cascade regulation of terminal adipocyte differentiation by three members of the C/EBP family of leucine zipper proteins. Genes Dev 1995;9:168-181.

14. Masuzaki $\mathrm{H}$, Paterson J, Shinyama $\mathrm{H}$, et al. A transgenic model of visceral obesity and the metabolic syndrome. Science 2001;294: 2166-2170.

15. Newell-Price J, Bertagna $X$, Grossman $A B$, et al. Cushing's syndrome. Lancet 2006;367:1605-1617.

16. Hauner H, Schmid P, Pfeiffer EF. Glucocorticoids and insulin promote the differentiation of human adipocyte precursor cells into fat cells. J Clin Endocrinol Metab 1987;64:832-835

17. Ito $S$, Suzuki $N$, Kato $S$, et al. Glucocorticoids induce the differentiation of a mesenchymal progenitor cell line, ROB-C26 into adipocytes and osteoblasts, but fail to induce terminal osteoblast differentiation. Bone 2007;40:84-92.

18. Yamamoto KR. Steroid receptor regulated transcription of specific genes and gene networks. Annu Rev Genet 1985;19:209-252.

19. Beato $M$, Herrlich $P$, Schutz $G$. Steroid hormone receptors: many actors in search of a plot. Cell 1995;83:851-857.
20. Karin M. New twists in gene regulation by glucocorticoid receptor: is DNA binding dispensable? Cell 1998;93:487-490.

21. McKay LI, Cidlowski JA. Molecular control of immune/inflammatory responses: interactions between nuclear factor-kappa B and steroid receptor-signaling pathways. Endocr Rev 1999;20:435-459.

22. De Bosscher K, Vanden Berghe W, Haegeman G. The interplay between the glucocorticoid receptor and nuclear factor-kappaB or activator protein-1: molecular mechanisms for gene repression. Endocr Rev 2003;24:488-522.

23. Barnes PJ. Corticosteroid effects on cell signalling. Eur Respir J 2006 27:413-426.

24. Heck S, Kullmann M, Gast A, et al. A distinct modulating domain in glucocorticoid receptor monomers in the repression of activity of the transcription factor AP-1. EMBO J 1994;13:4087-4095.

25. Reichardt HM, Kaestner $\mathrm{KH}$, Tuckermann J, et al. DNA binding of the glucocorticoid receptor is not essential for survival. Cell 1998;93: 531-541.

26. Banerjee SS, Feinberg MW, Watanabe $M$, et al. The Kruppel-like factor KLF2 inhibits peroxisome proliferator-activated receptor-gamma expression and adipogenesis. J Biol Chem 2003;278:2581-2584.

27. Oishi Y, Manabe I, Tobe K, et al. Kruppel-like transcription factor KLF5 is a key regulator of adipocyte differentiation. Cell Metab 2005;1:27-39.

28. Mori T, Sakaue $\mathrm{H}$, Iguchi $\mathrm{H}$, et al. Role of Kruppel-like factor 15 (KLF15) in transcriptional regulation of adipogenesis. J Biol Chem 2005;280: 12867-12875.

29. Gray S, Feinberg MW, Hull S, et al. The Kruppel-like factor KLF15 regulates the insulin-sensitive glucose transporter GLUT4. J Biol Chem 2002;277:34322-34328.

30. Gray S, Wang B, Orihuela Y, et al. Regulation of gluconeogenesis by Kruppel-like factor 15. Cell Metab 2007;5:305-312.

31. Reichardt HM, Kaestner $\mathrm{KH}$, Tuckermann J, et al. DNA binding of the glucocorticoid receptor is not essential for survival. Cell 1998;93: 531-541.

32. Pascussi JM, Busson-Le Coniat $M$, Maurel $P$, et al. Transcriptional analysis of the orphan nuclear receptor constitutive androstane receptor (NR1/3) gene promoter: identification of a distal glucocorticoid response element. Mol Endocrinol 2003;17:42-55.

33. Todaro GJ, Green H. Quantitative studies of the growth of mouse embryo cells in culture and their development into established lines. J Cell Biol 1963;17:299-313.

34. Ramirez-Zacarias JL, Castro-Munozledo F, Kuri-Harcuch W. Quantitation of adipose conversion and triglycerides by staining intracytoplasmic lipids with Oil red O. Histochemistry 1992;97:493-497.

35. Tuckermann JP, Kleiman A, Moriggl R, et al. Macrophages and neutrophils are the targets for immune suppression by glucocorticoids in contact allergy. J Clin Invest 2007;117:1381-1390.

36. Phuc Le P, Friedman JR, Schug J, et al. Glucocorticoid receptordependent gene regulatory networks. PLoS Genet 2005;1:e16.

37. Kassel O, Schneider S, Heilbock C, et al. A nuclear isoform of the focal adhesion LIM-domain protein Trip6 integrates activating and repressing signals at AP-1- and NF-kappaB-regulated promoters. Genes Dev 2004;18:2518-2528.

38. Fahnenstich J, Nandy A, Milde-Langosch K, et al. Promyelocytic leukaemia zinc finger protein (PLZF) is a glucocorticoid- and progesterone-induced transcription factor in human endometrial stromal cells and myometrial smooth muscle cells. Mol Hum Reprod 2003;9:611-623.

39. Baudry A, Yang ZZ, Hemmings BA. PKBalpha is required for adipose differentiation of mouse embryonic fibroblasts. J Cell Sci 2006;119: 889-897.

40. Frijters R, Fleuren W, Toonen EJ, et al. Prednisolone-induced differential gene expression in mouse liver carrying wild type or a dimerizationdefective glucocorticoid receptor. BMC Genomics 2010;11:359.

41. Opherk C, Tronche F, Kellendonk C, et al. Inactivation of the glucocorticoid receptor in hepatocytes leads to fasting hypoglycemia and ameliorates hyperglycemia in streptozotocininduced diabetes mellitus. Mol Endocrinol 2004;18:1346-1353.

42. Teshigawara K, Ogawa W, Mori T, et al. Role of Kruppel-like factor 15 in PEPCK gene expression in the liver. Biochem Biophys Res Commun 2005;327:920-926.

43. Yamamoto J, Ikeda $\mathrm{Y}$, Iguchi $\mathrm{H}$, et al. A Kruppel-like factor KLF15 contributes fasting-induced transcriptional activation of mitochondrial acetyl-CoA synthetase gene AceCS2. J Biol Chem 2004;279:16954-16962. 